\title{
Potential Biostimulant Effect of Clam Shells on Growth Promotion of Plantain PIF Seedlings (var. Big Ebanga \& Batard) and Relation to Black Sigatoka Disease Susceptibility
}

\author{
Cécile Annie Ewane ${ }^{1,2 *}$, Félix Ndongo', Katy Ngoula1, Paul Martial Tene Tayo1, \\ Stephen Obol Opiyo ${ }^{3}$, Thaddée Boudjeko ${ }^{1,2}$ \\ ${ }^{1}$ Laboratory of Phytoprotection and Plant Valorization, Biotechnology Center, University of Yaoundé 1, Messa-Yaoundé, \\ Cameroon \\ ${ }^{2}$ Department of Biochemistry, Faculty of Science, University of Yaoundé 1, Yaoundé, Cameroon \\ ${ }^{3}$ Molecular and Cellular Imaging Canter-Columbus, OARDC, The Ohio State University, Columbus, OH, USA \\ Email: *ccilany.ewane@gmail.com
}

How to cite this paper: Ewane, C.A., Ndongo, F., Ngoula, K., Tene Tayo, P.M., Obol Opiyo, S. and Boudjeko, T. (2019) Potential Biostimulant Effect of Clam Shells on Growth Promotion of Plantain PIF Seedlings (var. Big Ebanga \& Batard) and Relation to Black Sigatoka Disease Susceptibility. American Journal of Plant Sciences, 10, 1763-1788.

https://doi.org/10.4236/ajps.2019.1010125

Received: September 9, 2019

Accepted: October 15, 2019

Published: October 18, 2019

Copyright $\odot 2019$ by author(s) and Scientific Research Publishing Inc. This work is licensed under the Creative Commons Attribution International License (CC BY 4.0).

http://creativecommons.org/licenses/by/4.0/

\begin{abstract}
Plantain contributes significantly to income generation and food security for millions of people in the world. However, it faces problems of seedlings quantity, quality and availability. The innovation of the "plants issus de fragments de tiges" (PIF) technique could be a solution to these problems for small holders' farmers. The aim of this research is to evaluate the effect of clam shells through amendment of Batard and Big Ebanga PIF substrate, on the growth promotion of seedlings and their protection against black Sigatoka disease (BSD). Plantain PIF seedlings of the two varieties were grown in a substrate amended with $1 \%$ concentration of the clam shells powder in the presence of negative control in the sterile and non-sterile conditions. Agromorphological characteristics, susceptibility level to BSD, total proteins and polyphenols content were assessed. Because of the presence of clam shells in the substrates, explants germinated quickly, generated high number of shoots, grew taller by $32 \%$, with a diameter of pseudo stems of $30 \%$, and area of leaves of $18 \%$ compared to control. In addition, the seedlings were less susceptible to BSD by $73 \%$ compared to those of controls. The treatment seems to allow the accumulation of larger amounts of total proteins and polyphenols before inoculation and after inoculation that could participate in the growth promotion and the reduction of plant's susceptibility level. Clam shells treatment acts as a biofertilizer/biopesticide and could be helpful to boost production of plantain seedlings, the use of the by-products of fishing in agriculture and helps alleviate poverty of small holders' farmers.
\end{abstract}




\section{Keywords}

Plantain (Musa spp.), PIF Seedlings, Clam Shells, Biostimulant Potential, Biofertilizer, Biopesticide, Black Sigatoka Disease

\section{Introduction}

Bananas are one of the most important fruit crops in the world and are perennial monocotyledonous plants that grow in tropical and subtropical regions. The Musaceae family (Musa spp.) regroups diverse cultivar amongst which the dessert banana that can be eaten raw when they are ripe, sweet and easily digestible, and cooking banana type like plantains which are usually starchy even when ripped and need to be cooked before consumption. Plantain contributes significantly to income generation and food security for millions of people in tropical and sub-tropical countries. It belongs to the subgroup of hybrid triploid AAB generated by hybridization between wild ancestors Musa acuminata (genome AA) and Musa balbisiana (genome BB) [1]. Plantain with a high energy value and a rich mineral, dietary fiber and vitamin content, plays a vital role in contributing to food security for more than 250 million people in Central and West Africa.

Cameroon is ranked 2nd in the world (4.54 million tons in 2017) in terms of plantain production and the first in the Central African Economic and Monetary Community (CEMAC) zone [2]. Plantain consumption in CEMAC zone is very high as well as income generation for millions of people in these regions. The per capita consumption of plantain in Gabon and Cameroon is over 203 $\mathrm{kg} /$ person/year nowadays [2] and was respectively 159 and $126 \mathrm{~kg} /$ person/year in 2012 for both countries. This high consumption has caused demand of plantain to largely outweigh supply, resulting in very high prices for the commodity on local, urban and trans-border markets. Indeed, plantain prices have recently increased with a peak price of CFA F 322 (US\$ 0.63) per kg in August 2017, it was 2.3 times higher than that of six months before in February 2017 [3] and 5.3 times higher than that of the highest prices in 2002 [4]. Consumers thus, turn to consume more rice which is not commonly produced in these countries and is mostly imported than plantain which could be produced even behind houses in family farms. Plantain production for food or for sale on local markets is managed by smallholder farmers in small sized family farm holdings and in-home gardens which are characterized by low productivity. As a result, demanding largely outstrips supply provokes very high prices for this commodity on rural, urban and trans-border markets. There is a great need to improve the performance of this crop from about 10 tons/ha/year to more than 30 tons/ha/year. To meet up with this demand, we need to create new plantations whereas the creation of these new plantations is difficult because of the problem of unavailability of seedlings in quantity, but also seedlings of quality. 
In the traditional practice, plantains seedlings come from suckers extracted from field in production. Banana cultivars, mainly the triploids have a very low fecundity and there is a need of vegetative multiplication technique for massive production, notably the micropropagation and the macropropagation to obtain respectively vitroplants (plants from tissue culture) and vivoplants (plants from axillary buds). The use of vitroplants in intensive agriculture to mitigate the problem of seedlings availability especially the clean ones is very expensive and not affordable to smallholder farmer. An innovative macropropagation technique called PIF (Plants Issus de Fragment de tiges) is that plants resulting from stem fragments were set up by the African Centre for Research on Bananaplantain (CARBAP) located in Njombé (Cameroon). This technique has been recommended for few years now to farmers for massive production of seedlings at low cost, within a very short period of time (2 to 3 months) and quickly generates plantains seedling in large amounts [5]. Indeed, one plantain sucker can produce between 20 and 100 seedlings depending on the variety of plantain and the experience of the farmer. However, despite these advantages, seedlings produced by PIF technique face many problems during acclimatization, as well as contamination of the seedlings on farmlands. These problems faced by PIF seedlings could be responsible of plants mortality of about $60 \%$ during the establishment of new plantations and are now rejected by some farmers. Even when plantains seedlings are generated from PIF, they are disseminated on farmlands in a soil that often contains pathogenic microorganisms, causing their attack by diseases. In addition, the position (in the centre or at the ends) of the seedling on explants influences the vigour of the plant.

Banana tree is permanently threatened by Mycosphaerella leaf spot disease, which influences the fruit's physiology, the green life of bananas fruit and the incidence of diseases [6]. Black Sigatoka disease (BSD) is a leaf spot disease of bananas caused by the ascomycetous fungi Mycosphaerella fijiensis, a virulent, an invasive and predominant pathogen in all banana-growing countries. In case of severe infections, this foliar disease can lead to a substantial reduction of the leaf area. Moreover, BSD is the most economically destructive disease of bananas, which accounts for loses of bananas production estimated at about 50\% [7]. The extensive use of chemical inputs (weed-killers, fertilizers, fungicides, pesticides) in PIF seedlings production and on farmlands is unattractive. Indeed, commonly used in agriculture to increase plant productivity and resistance against pathogens they can cause irreversible damage to the ecosystems due to their accumulation in the environment and in the living organisms, can induce the appearance of resistance in plant pathogens increasing then the use dosage of existing products [8] and are costfull to the smallholder farmers.

So far, the potential impact of clam shells in agriculture as biofertilizer and/or as biocontrol agent has received limited attention. However, a recent study carried out in Cameroon has demonstrated that snail shell powder has a strong influence on cocoa growth and resistance in nurseries by acting as a biofertilizer and as a biofungicide in the control of cocoa black pod disease [9]. Moreover, 
the clam shells are abundant waste products regularly found along the coasts of rivers that become pollutants for the environment when accumulated for a long time. The use of the by-products of fishing in agriculture could be a solution to clean the river around and promote a green agriculture, since they have very good biological properties amongst which antimicrobial ones. In fact, the main components of crustacean shells are chitin (15\% - 40\%), protein $(20 \%-40 \%)$, calcium and magnesium carbonate (20\% - 50\%), together with other minor constituents, such as astaxanthin, lipids and other minerals [10]. Chitin is a linear chain polysaccharide composed of units of $\mathrm{N}$-acetyl-2-dioxin-D-glucopyranoside linked by glycosidic $\beta(1 \rightarrow 4)$ bonds. Moreover, it's a renewable material from natural sources and is biodegradable, nontoxic and insoluble in water and many organic solvents [11]. A plant biostimulant is any substance or microorganism applied to plants with the aim to enhance nutrition efficiency, abiotic stress tolerance and/or crop quality traits, regardless of its nutrients content [12]. Therefore, the clam shells are good candidate for PIF plantain seedlings biostimulation regarding on their properties. The use of the biostimulant potential of clam shells in the production of PIF seedlings can be a new approach to improve the quality of plantain seedlings while enhancing their quantity.

The aim of this work is to examine the potential biostimulant effect of clam shells through amendment of PIF substrate, on the growth promotion of plantain seedlings in nursery and on their protection against diseases, notably black sigatoka disease. This work was conducted in Yaoundé, Cameroon from September 2014 to March 2015 and September 2015 to March 2016 respectively for the Big Ebanga variety and the Batard variety.

\section{Materials and Methods}

\subsection{Materials}

Suckers of plantain (Musa spp., genome AAB) of Big Ebanga and Batard varieties were obtained respectively from Mbam and Kim division (Ntui) and Lékié division (Obala) of Centre region of Cameroon. These varieties were selected and used during this experiment due to their short cycle of production and their capacity to produce a great number of plantain seedlings.

The clam shells constituting our organic matter come from the municipality of Mouanko, located in the Littoral region and more specifically in the Sanaga Maritime division, precisely on the north bank of the Sanaga River about twenty kilometers east of its mouth in the Gulf of Guinea. The clam shells powder was obtained as follow: the fresh clams were washed, dried in the sun, broken into large pieces, then reduced to powder and finally sifted.

Strain of Mycosphaerella fijiensis, causal agent of black Sigatoka disease was provided by the African Centre for Research on Bananas and Plantains (CARBAP) of Njombé in the Littoral region of Cameroon.

The substrates used for this experiment (sawdust, sand and black soil) were sterilized in an oven at different temperatures and time intervals as follow: 04 
hours at $121^{\circ} \mathrm{C}$ for $3 \mathrm{~kg}$ sawdust, 05 hours at $121^{\circ} \mathrm{C}$ for $10 \mathrm{~kg}$ of sand and 09 hours at $121^{\circ} \mathrm{C}$ for $25 \mathrm{~kg}$ of black soil. The soil used in this experiment was collected from Yaoundé (Centre region, Cameroon). The white sawdust was used for growth of banana seedlings in the greenhouse. A mixture at a ratio of $2 / 3$ of black soil and $1 / 3$ of sand was used as substrate for the growth of seedlings in the shade.

\subsection{Experimental Design}

This study was conducted in the Centre Region of Cameroon (Yaoundé), located in the agro-ecological zone known as wet Rainforest with Bimodal Rainfall. The acclimation phase for plantain seedlings under shade was extended over the period from November to January marked by high temperatures $\left(26^{\circ} \mathrm{C}-30^{\circ} \mathrm{C}\right)$ and low rainfall ( $25-80 \mathrm{~mm} / \mathrm{month})$. The other phases of the study were conducted under controlled conditions that are in the laboratory and in the greenhouse.

The banana propagation by the PIF method is done in two phases:

- A germination phase of the explants in the greenhouse;

- A phase of acclimatization of the seedlings under shade.

We have the same experimental device both in the greenhouse and in the shade, and each treatment was considered as an experimental unit (EU). However, differences were observed in:

1) The substrate to amend:

- Sawdust in greenhouse for the production of the PIF seedlings;

- Black soil and sand for survey of the seedling's growth in the shade.

2) The number of plants per experimental unit (EU):

- In the greenhouse, three (03) explants per EU (propagator) were introduced for production of seedlings in the greenhouse;

- In the shade, at least three (3) plants per EU (plastic planter bags).

Our experiment was done on a completely randomized block device with two (02) treatments that are: $1 \%$ clam shells (CS) powder amendments and the control (EU not receiving any treatment) and at two (02) blocks: a sterilized substrate block (B1, SS, controlled condition) and a non sterilized substrate block (B2, nSS, farmer condition). The treatments for both blocks and each variety were:

- Sterile Substrates + Clam shells (SS + CS);

- Sterile Substrates only as control (SS);

- Non-Sterile Substrates + Clam shells (nSS + CS);

- Non-Sterile Substrates only as control (nSS).

The plantain suckers of Batard and Big Ebanga varieties were prepared following the PIF technique recommendation in order to obtain the explants in 3 successive steps: trimming, shelling and the trauma of the shoot apical meristem following the method of [13].

The different experimental units were finally classified by block on the shelves in a greenhouse and covered with a white and transparent plastic. Explants 
tracking (watering) in the greenhouse allowed them to germinate and produce seedlings.

\subsection{Assessment of Germination Rate of Explants in the Greenhouse}

The evaluation of germination parameters (germination rate and number of PIF seedlings produce) per experimental unit was done after every seven days starting from the second week of introduction of explants in the greenhouse. This evaluation was done for a period of four weeks. We proceeded by counting the germinated bulbs and the number of seedlings emitted in each experimental unit (propagator). The germination rate and the number of seedlings emitted for each EU were evaluated. The ratio of the number of germinated bulbs and the total number of initial bulbs multiplied by 100 , gave us the germination rate for each EU expressed as a percentage. However, a period of six weeks was sufficient for all the explants to produce PIF seedlings. After eight weeks, the seedlings from the greenhouse were weaned in plastic planter bags at the state of two to three small open leaves per seedling and from three to four radicles, then transferred in the shade following the same experimental disposal as in the greenhouse.

\subsection{Evaluation of Agromorphological Characteristics}

For each experimental unit, three plants were selected and labelled in the shade. The effect of different treatments on the growth and development of the seedlings was evaluated by measuring different agromorphological characteristics:

- The height of the seedlings;

- The diameter of the seedlings pseudo-stems;

- The total area of the seedlings' leaves.

The total leaf surface $\left({ }_{T} L S\right)$ of each plantain seedling was determined using the length $(L)$, the width $(W)$ and the number of leaves and 0.8 and 0.662 being constants following the formula of [1]: ${ }_{T} L S=L \times W \times 0.8 \times$ number of leaves $\times$ $0.662\left(\mathrm{~cm}^{2}\right)$. Its average value was taken as a measure of total area of the seedling's leaves.

The evaluation was done every seven days starting from the day the seedlings entered the shade and was done for a period of seven weeks.

\subsection{Evaluation of Susceptibility of Plantain Seedlings to Mycosphaerella fijiensis}

\subsubsection{Fungal Strain}

The strain of $M$. fijiensis was used for artificial inoculations. All the cultures were done in Petri dishes containing Potato Dextrose Agar medium (PDA) and were incubated under a white light at $25^{\circ} \mathrm{C}$ for 21 days. Thereafter, the mycelia disks of the strain were transplanted 3 times on the modified V8 medium ( $\mathrm{pH}$ 6.64) [7] and incubated at $25^{\circ} \mathrm{C}$ for 14 days to obtain pure strain, which were conserved at $4^{\circ} \mathrm{C}$. After the growth of $M$. fijiensis, the mycelia disks were taken with the help of a punch from the Petri dishes in an aseptic manner and were in- 
troduce in tubes containing physiological water $(\mathrm{NaCl} 9 \mathrm{~g} / \mathrm{L})$. The mixture was homogenized with the help of a vortex for 15 minutes that permitted the formation of spores. A drop of the zoospore's suspension was calibrated with a Neubauer cell at a concentration of $10^{6}$ zoospores/mL for BSD inoculations.

\subsubsection{Evaluation of Susceptibility to BSD}

The susceptibility of plantain seedlings to BSD was evaluated through artificial inoculation of the leaves of plantain seedlings with $M$. fijiensis. The leaves of the same age period (12 weeks) were used for inoculation and three plants per treatment were used (three leaves per treatment). Before inoculation, a leaf of each plant was detached and conserved at $-45^{\circ} \mathrm{C}$ in a plastic sachet for biochemical analysis of the before inoculation stage. One hour after the preparation of the zoospore's solution according to the protocol of [7], a $100 \mu \mathrm{L}$ droplet of $M$. fijiensis suspension was then deposit midway through the exposed surface of the leaf. The infected leaves were kept under controlled condition of relative humidity in the greenhouse. After inoculation, the follow up of the evolution of necrosis was done by measuring the length $(L)$ and the width $(W)$ of the necrotic surface after every two days and for every seven days from 14 days in order to visualized the rot spreading on the leaf's surface and it was during a period of four weeks. The "necrotic surface area" $(N S A)$ in $\left(\mathrm{mm}^{2}\right)$ was calculated for each measurement by assuming a rectangular shape to the necrosis as in the formula of [14]: $N S A=L \times W$.

\subsection{Biochemical Analyses}

Biochemical analyses were carried out in two stages (before inoculation and after inoculation) on the whole leaves. The leaves samples involved were cut at $1 \mathrm{~cm}$ beyond the necrosis point or beyond the marked scar (sections with no symptoms). For biochemical analyses, each treatment was repeated trice.

\subsubsection{Determination of the Content of Total Native Protein}

Extraction samples were carried out according to the method reported by [15] with modification. This method allows the extraction of the total native protein. $1 \mathrm{~g}$ of fresh leaf was placed in a mortar and ground with a pestle in $10 \mathrm{~mL}$ Tris-Maleate buffer $(0.1 \mathrm{mM}, \mathrm{pH} 7.2)$ at $4^{\circ} \mathrm{C}$. The mixture was then vortexed for $10 \mathrm{~min}$ and centrifuged at $10.000 \mathrm{~g}$ for $25 \mathrm{~min}$ at $4^{\circ} \mathrm{C}$ (Beckmann-Coulter microfuge $20 \mathrm{R}$ centrifuge). The supernatant was conserved while the pellet was centrifuged following the same conditions. Both supernatants were mixed and supplemented with 0.4 volume of n-butanol and 1/10 of $3 \mathrm{M}$ sodium acetate buffer, $\mathrm{pH} 4.5$. The samples were kept on ice for $30 \mathrm{~min}$ with agitation every 10 min followed by centrifugation at $10.000 \mathrm{~g}$ for $15 \mathrm{~min}$ and stored at $4^{\circ} \mathrm{C}$. The quantity of total proteins was determined according to the method of [16] with Coomassie blue G250. The absorbance was measured at $595 \mathrm{~nm}$ using the Shimadzu Spectrophotometer UV-1605 against a control in which the extract was replaced by distilled water. The protein concentration was expressed in $\mathrm{mg}$ 
equivalent (Eq) of bovine serum albumin (BSA) per $\mathrm{g}$ of fresh weight (FW).

\subsubsection{Determination of the Content of Total Phenolic Compounds}

Extraction samples were carried out according to the method reported by [17]. This method allows the extraction of the total phenolic compounds. $1 \mathrm{~g}$ of fresh leaf was pounded at $4^{\circ} \mathrm{C}$ in $10 \mathrm{~mL}$ methanol $80 \%(\mathrm{~V} / \mathrm{V})$. The mixture was then vortexed for $10 \mathrm{~min}$ and centrifuged at $10.000 \mathrm{~g}$ for $10 \mathrm{~min}$ (Beckmann-Coulter microfuge $20 \mathrm{R}$ centrifuge). The supernatant was conserved while the pellet was centrifuged following the same conditions two other times. The three supernatants were mixed to make up the total extract of phenolic compounds. The concentration of phenolic compounds was determined spectrophotometrically at $760 \mathrm{~nm}$ against a control where the extract was replaced by distilled water following the protocol of [18] using the Folin-Ciocalteu reagent. The concentration of total polyphenols was measured in mg equivalent (Eq) of gallic acid per $\mathrm{g}$ of fresh weight $(\mathrm{FW})$.

\subsection{Statistical Analyses}

The effects of clam shells on plantain seedlings growth, susceptibility to BSD and total proteins and polyphenols were analysed. The different variables were analysed by subjection of the value (germination percentage, number of shoots, height and diameter of seedlings, leaves surface area, necrotic surface area, total proteins and total polyphenolic) to mixed three-way analysis of variance (ANOVA) performed with XLSTAT software, each plant being taken as experimental unit and variety, treatment and day as factors. Multiple comparisons of the means were done by applying Tukey's test at $5 \%$ probability level. Pearson correlation analysis between the different variables was also performed with XLSTAT software.

\section{Results}

\subsection{Effect of Clam Shells on the PIF Seedlings Growth Promotion}

\subsubsection{Effect of Clam Shells on the Germination Rate of Explants in the Green House}

The variety, the treatment and the day were found to significantly influence $(P<$ $0.0001)$ germination rate and the number of shoots with respective $R^{2}$ values of 1 and 0.98 and the most influential variable was the day. The percentage of germination and the number of shoots were consistently higher in the treated PIF substrates compared with the untreated ones. Hence, two statistically different groups were distinguished between the treated and the untreated PIF seedlings regardless the condition. Controlled condition (SS and SS + CS) and non-controlled condition (nSS and nSS + CS) differed by about 33\% germination respectively for the treated substrate 14 days after seeding (das) and for the number of shoots, this difference was very weak on the 42 days after weaning (daw) (Table 1).

Treatment effect was especially marked for the Batard variety with $100 \%$ of 
germination obtained 14 das for the treatment SS + CS. However, 21 das was enough for total germination regardless of variety as confirmed by the significant interaction $(P<0.0001)$ between variety and treatment, variety and day, treatment and day, and variety, treatment and day (Table 2 and Figure 1). The total germination (100\%) was obtained in the untreated substrates (SS and nSS) 28 das in both varieties.

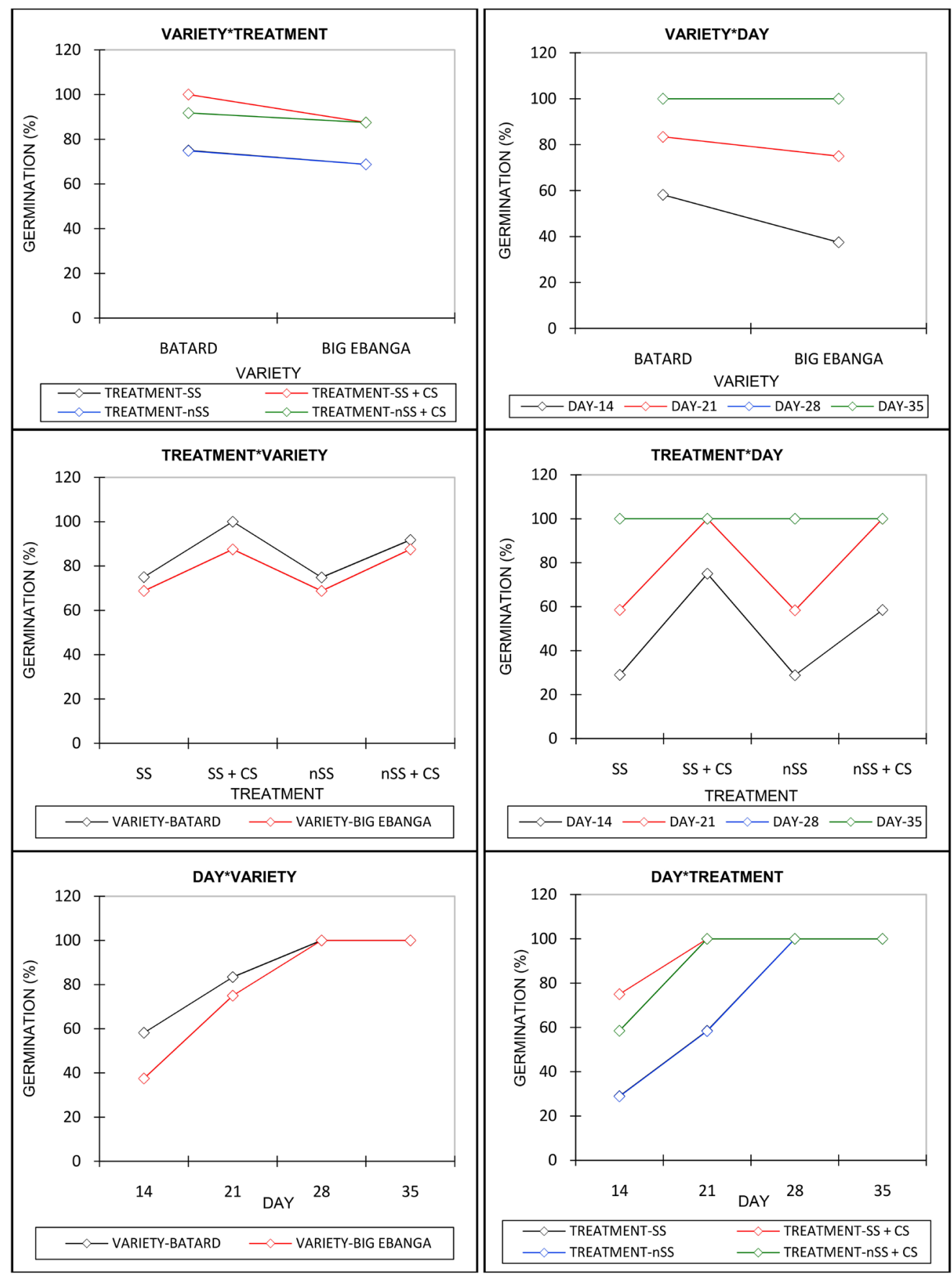

Figure 1. Interaction plots (variety, treatment and day) of the clam shells effects on the percentage of germination in both varieties (Batard and Big Ebanga) of plantain PIF seedlings in course of time. Each point represents the average mean of three replicates for each treatment. 
Table 1. Difference of the mean values of the different variables (percentage of germination, number of shoots, height of shoots, diameter of pseudo-stems, area of leaves, BSD severity, total proteins and total polyphenols) between the sterile substrate condition (SS and SS + CS) and non-sterile substrate condition (nSS and nSS + CS) in the Batard and the Big Ebanga varieties.

\begin{tabular}{|c|c|c|c|c|c|c|c|c|c|}
\hline Variable & Variety & Day/stage & Ss & Nss & Difference 1 & Ss $+c s$ & Nss + cs & Difference2 & Global difference \\
\hline \multirow[t]{2}{*}{$\%$ Germination } & Batard & 14 & 33.0 & 33.0 & 0.0 & 100.0 & 67.0 & 33.0 & 33.0 \\
\hline & Big ebanga & 14 & 0.0 & 0.0 & 0.0 & 0.0 & 0.0 & 0.0 & 0.0 \\
\hline \multirow{2}{*}{ Number of shoots } & Batard & 42 & 9.0 & 8.0 & 1.0 & 15.3 & 18.3 & 3.0 & 2.0 \\
\hline & Big ebanga & 42 & 13.3 & 14.3 & 1.0 & 18.3 & 17.3 & 1.0 & 0.0 \\
\hline \multirow[t]{2}{*}{ Height $(\mathrm{cm})$} & Batard & 42 & 16.4 & 15.9 & 0.5 & 20.6 & 21.2 & 0.6 & 0.1 \\
\hline & Big ebanga & 42 & 15.2 & 12.3 & 2.8 & 16.3 & 16.5 & 0.2 & 2.7 \\
\hline \multirow[t]{2}{*}{ Diameter (mm) } & Batard & 42 & 13.8 & 15.3 & 1.5 & 16.5 & 16.6 & 0.1 & 1.4 \\
\hline & Big ebanga & 42 & 13.8 & 13.2 & 0.6 & 16.2 & 15.0 & 1.2 & 0.6 \\
\hline \multirow[t]{2}{*}{ Area of leaves $\left(\mathrm{cm}^{2}\right)$} & Batard & 42 & 167.0 & 147.5 & 19.6 & 301.1 & 270.4 & 30.7 & 11.1 \\
\hline & Big ebanga & 42 & 289.7 & 364.5 & 74.8 & 522.4 & 381.5 & 140.9 & 66.1 \\
\hline \multirow[t]{2}{*}{ Bsd severity $\left(\mathrm{cm}^{2}\right)$} & Batard & 28 & 31.4 & 35.4 & 4.0 & 4.3 & 6.1 & 1.9 & 2.2 \\
\hline & Big ebanga & 28 & 23.2 & 24.3 & 1.1 & 2.9 & 6.7 & 3.7 & 2.7 \\
\hline Total proteins & Batard & BI & 1.3 & 1.0 & 0.3 & 3.3 & 2.5 & 0.8 & 0.5 \\
\hline \multirow[t]{3}{*}{ (Mg eq bsa/g fw) } & Batard & AI & 6.7 & 6.0 & 0.6 & 7.2 & 7.1 & 0.1 & 0.6 \\
\hline & Big ebanga & BI & 3.2 & 4.5 & 1.3 & 5.0 & 5.7 & 0.7 & 0.6 \\
\hline & Big ebanga & AI & 2.6 & 4.0 & 1.4 & 4.5 & 5.3 & 0.8 & 0.6 \\
\hline Total polyphenols & Batard & BI & 0.6 & 1.0 & 0.4 & 0.9 & 1.2 & 0.3 & 0.1 \\
\hline \multirow[t]{3}{*}{ (Mg eq cat/g fw) } & Batard & AI & 2.0 & 1.7 & 0.3 & 2.6 & 2.3 & 0.4 & 0.1 \\
\hline & Big ebanga & BI & 2.0 & 2.5 & 0.5 & 4.9 & 5.6 & 0.7 & 0.2 \\
\hline & Big ebanga & AI & 2.4 & 3.0 & 0,7 & 5.4 & 6.7 & 1.4 & 0.7 \\
\hline
\end{tabular}

BI: before inoculation, AI: after inoculation.

Table 2. Variance analysis of clam shells treatments effects on the percentage of germination and number of cumulative shoots of plantain PIF seedlings in the greenhouse.

\begin{tabular}{|c|c|c|c|c|c|c|}
\hline \multirow[b]{2}{*}{ Source } & \multicolumn{3}{|c|}{ Percentage of germination $/ R^{2}=100 \%$} & \multicolumn{3}{|c|}{ Number of shoots $/ R^{2}=98 \%$} \\
\hline & $\mathrm{DF}$ & $F$ & $P$ & $\mathrm{DF}$ & $F$ & $P$ \\
\hline Variety & 1 & 1416 & $<0.0001$ & 1 & 438 & $<0.0001$ \\
\hline Treatment & 3 & 3596 & $<0.0001$ & 3 & 175 & $<0.0001$ \\
\hline Day & 3 & 16,279 & $<0.0001$ & 4 & 561 & $<0.0001$ \\
\hline Variety*treatment & 3 & 87 & $<0.0001$ & 3 & 7 & 0 \\
\hline Variety ${ }^{\star}$ day & 3 & 640 & $<0.0001$ & 4 & 16 & $<0.0001$ \\
\hline Treatment*day & 9 & 1255 & $<0.0001$ & 12 & 6 & $<0.0001$ \\
\hline Variety $^{\star}$ treatment $^{\star}$ day & 9 & 248 & $<0.0001$ & 12 & 1 & 0 \\
\hline
\end{tabular}

$\mathrm{DF}$ is the degree of freedom; $F$ is the value of $\mathrm{F}$ test and $P$ is the probability. 
Treatment effect was especially marked for the Big Ebanga variety that generate more shoots in the treated PIF substrate 42 das (average value: 17.83) compared to the Batard variety (average value: 16.83) as confirmed by the significant interaction $(P<0.0001)$ between variety and day, treatment and day, although no significant interaction was observed between variety, treatment and day (Table 2 and Figure 2).
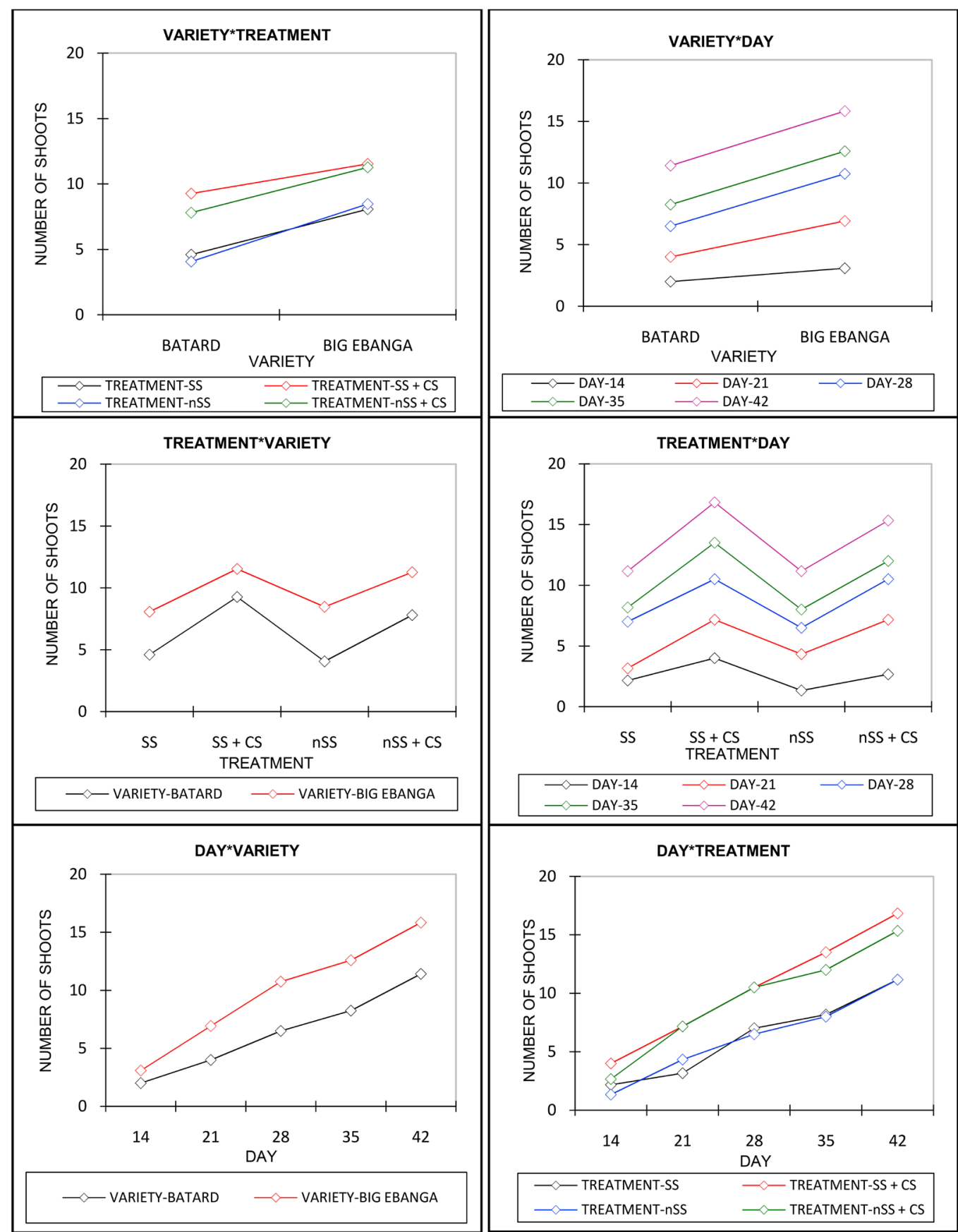

Figure 2. Interaction plots (variety, treatment and day) of the clam shells effects on the number of cumulative shoots in both varieties (Batard and Big Ebanga) of plantain PIF seedlings in course of time. Each point represents the average mean of three replicates for each treatment. 


\subsubsection{Effect of Clam Shells on the Agromorphological Characteristics of PIF Seedlings}

The variety, the treatment and the day were found to significantly influence $(P<$ 0.0001) PIF seedlings agromorphological characteristics with respective $R^{2}$ values of $0.99,0.99$ and 1 (Table 3), and the most influential variable was the day. The height, the diameter and the leaves surface area were consistently higher in the treated PIF seedlings compared with the untreated ones. Hence, two statistically different groups were distinguished between the treated and the untreated PIF seedlings for all the agromorphological characteristics. The difference between the controlled condition (SS and SS + CS) and non-controlled condition (nSS and nSS + CS) was very insignificant for height and diameter of pseudostems and less than $15 \%$ difference for the leaves area surface (Table 1).

Treatment effect was especially marked for the Batard variety that had seedlings with higher height and diameter of pseudo-stems 42 daw (average value: respectively $20.93 \mathrm{~cm}$ and $16.57 \mathrm{~mm}$ ) compared to the Batard variety (average value: respectively $16.41 \mathrm{~cm}$ and $15.6 \mathrm{~mm}$ ) as confirmed by the significant interaction $(P<0.0001)$ between variety and treatment, variety and day, treatment and day, and variety, treatment and day (Table 3, Figure 3 and Figure 4).

Treatment effect was especially marked for the Big Ebanga variety that had seedlings with consistently higher leaves surface area 42 daw (average value: $451.95 \mathrm{~cm}^{2}$ ) compared to the Batard variety (average value: $285.79 \mathrm{~cm}^{2}$ ) as confirmed by the significant interaction $(P<0.0001)$ between variety and treatment, variety and day, treatment and day, and variety, treatment and day (Table 3 and Figure 5).

\subsection{Effect of Clam Shells on the PIF Seedlings Protection against BSD}

\subsubsection{Effect of Clam Shells on the Susceptibility of PIF Seedlings to M. fijiensis}

The variety, the treatment and the day were found to very significantly influence $(P<0.0001)$ PIF seedlings susceptibility to $M$. fijiensis with $\mathrm{R}^{2}$ value of 0.97 (Table 4 ) and the most influential variable was the day. The black Sigatoka disease

Table 3. Variance analysis of clam shells treatments effects on the agromorphological characteristics (height, diameter of pseudo-stems, foliar surface area of leaves) of plantain PIF seedlings in the shade.

\begin{tabular}{|c|c|c|c|c|c|c|c|c|c|}
\hline \multirow[b]{2}{*}{ Source } & \multicolumn{3}{|c|}{ Height of shoots $(\mathrm{cm}) / \mathrm{R}^{2}=99 \%$} & \multicolumn{6}{|c|}{ Diameter of shoots $(\mathrm{mm}) / \mathrm{R}^{2}=99 \%$ Area of leaves $\left(\mathrm{mm}^{2}\right) / \mathrm{R}^{2}=100 \%$} \\
\hline & $\mathrm{DF}$ & $F$ & $P$ & $\mathrm{DF}$ & $F$ & $P$ & $\mathrm{DF}$ & $F$ & $P$ \\
\hline Variety & 1 & 2925 & $<0.0001$ & 1 & 720 & $<0.0001$ & 1 & 264,995 & $<0.0001$ \\
\hline Treatment & 3 & 1791 & $<0.0001$ & 3 & 738 & $<0.0001$ & 3 & 85,686 & $<0.0001$ \\
\hline Day & 6 & 1953 & $<0.0001$ & 6 & 860 & $<0.0001$ & 6 & 271,967 & $<0.0001$ \\
\hline Variety*treatment & 3 & 325 & $<0.0001$ & 3 & 86 & $<0.0001$ & 3 & 4349 & $<0.0001$ \\
\hline Variety ${ }^{*}$ day & 6 & 69 & $<0.0001$ & 6 & 6 & $<0.0001$ & 6 & 26,040 & $<0.0001$ \\
\hline Treatment $^{\star}$ day & 18 & 34 & $<0.0001$ & 18 & 6 & $<0.0001$ & 18 & 5942 & $<0.0001$ \\
\hline Variety ${ }^{\star}$ treatment ${ }^{*}$ day & 18 & 10 & $<0.0001$ & 18 & 5 & $<0.0001$ & 18 & 1191 & $<0.0001$ \\
\hline
\end{tabular}

$\mathrm{DF}$ is the degree of freedom; $F$ is the value of $\mathrm{F}$ test and $P$ is the probability. 
Table 4. Variance analysis of clam shells treatments effects on the plantain PIF seedlings susceptibility to black Sigatoka disease.

\begin{tabular}{lccc}
\hline & \multicolumn{3}{c}{ BSD severity $\left(\mathrm{cm}^{2}\right) / \mathbf{R}^{2}=\mathbf{9 7 \%}$} \\
\hline Source & DF & $F$ & $P$ \\
\hline Variety & 1 & 70 & $<0.0001$ \\
Treatment & 3 & 396 & $<0.0001$ \\
Day & 9 & 330 & $<0.0001$ \\
Variety ${ }^{\star}$ treatment & 3 & 20 & $<0.0001$ \\
Variety $^{\star}$ day & 9 & 8 & $<0.0001$ \\
Treatment $^{*}$ day & 27 & 56 & $<0.0001$ \\
Variety $^{\star}$ treatment & \\
\end{tabular}

$\mathrm{DF}$ is the degree of freedom; $F$ is the value of $\mathrm{F}$ test and $P$ is the probability.
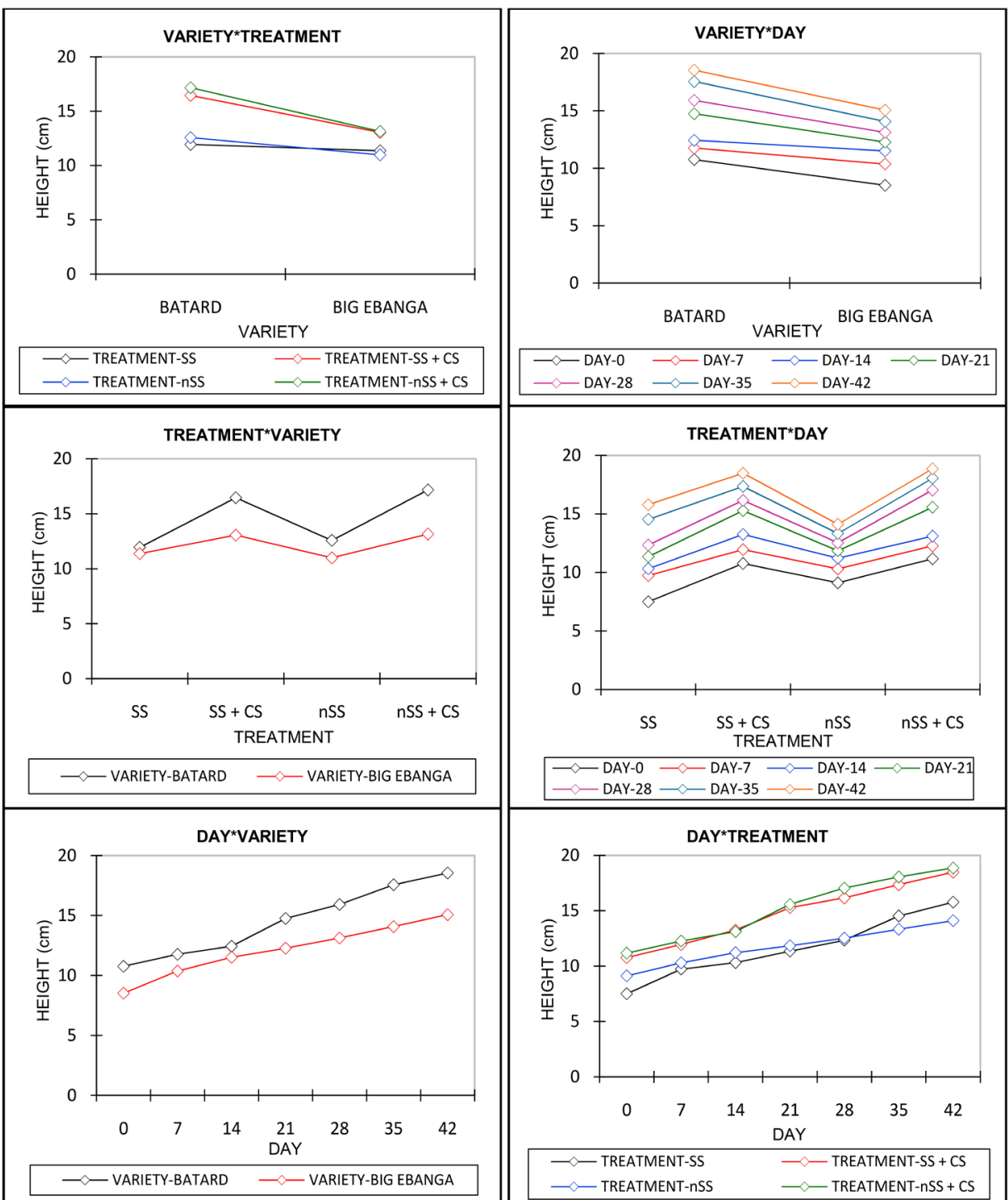

$\leadsto$ DAY-0 $\multimap$ DAY-7 $\rightleftharpoons$ DAY-14 $\prec$ DAY-21 $\sim$ DAY-28 $\sim$ DAY-35 $\rightleftharpoons$ DAY-42

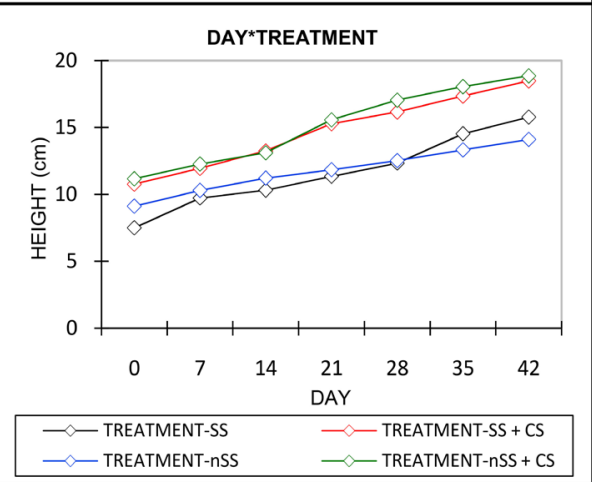

Figure 3. Interaction plots (variety, treatment and day) of the clam shells effects on the height of plantain PIF seedlings in both varieties (Batard and Big Ebanga) in course of time. Each point represents the average mean of three replicates for each treatment. 
severity was consistently lower in the treated PIF seedlings compared with the untreated ones. Hence, two very statistically different groups were distinguished between the treated and the untreated PIF seedlings. The difference between the level of severity in the controlled condition (SS and SS + CS) and non-controlled condition (nSS and nSS + CS) was very weak (Table 1).
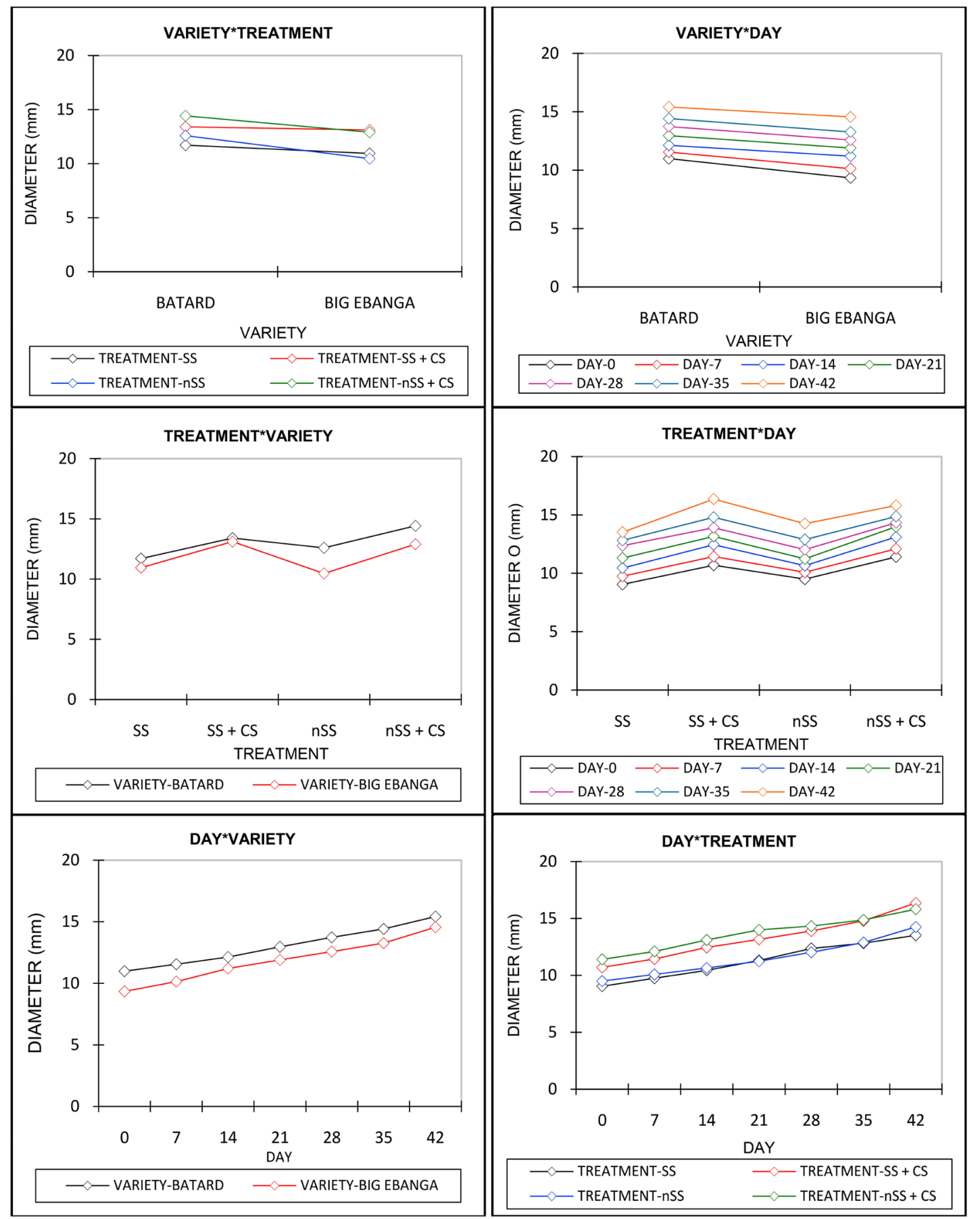

Figure 4. Interaction plots (variety, treatment and day) of the clam shells effects on the diameter of plantain PIF seedlings pseudo term in both varieties (Batard and Big Ebanga) in course of time. Each point represents the average mean of three replicates for each treatment. 
Treatment effect was especially marked for the Big Ebanga variety that had seedlings with consistently lower necrotic surface area 42 daw (average value: $4.80 \mathrm{~cm}^{2}$ ) compared to the Batard variety (average value: $5.18 \mathrm{~cm}^{2}$ ) as confirmed by the significant interaction $(P<0.0001)$ between variety and treatment, variety and day, treatment and day, although no significant interaction was observed between variety, treatment and day (Table 4 and Figure 6).

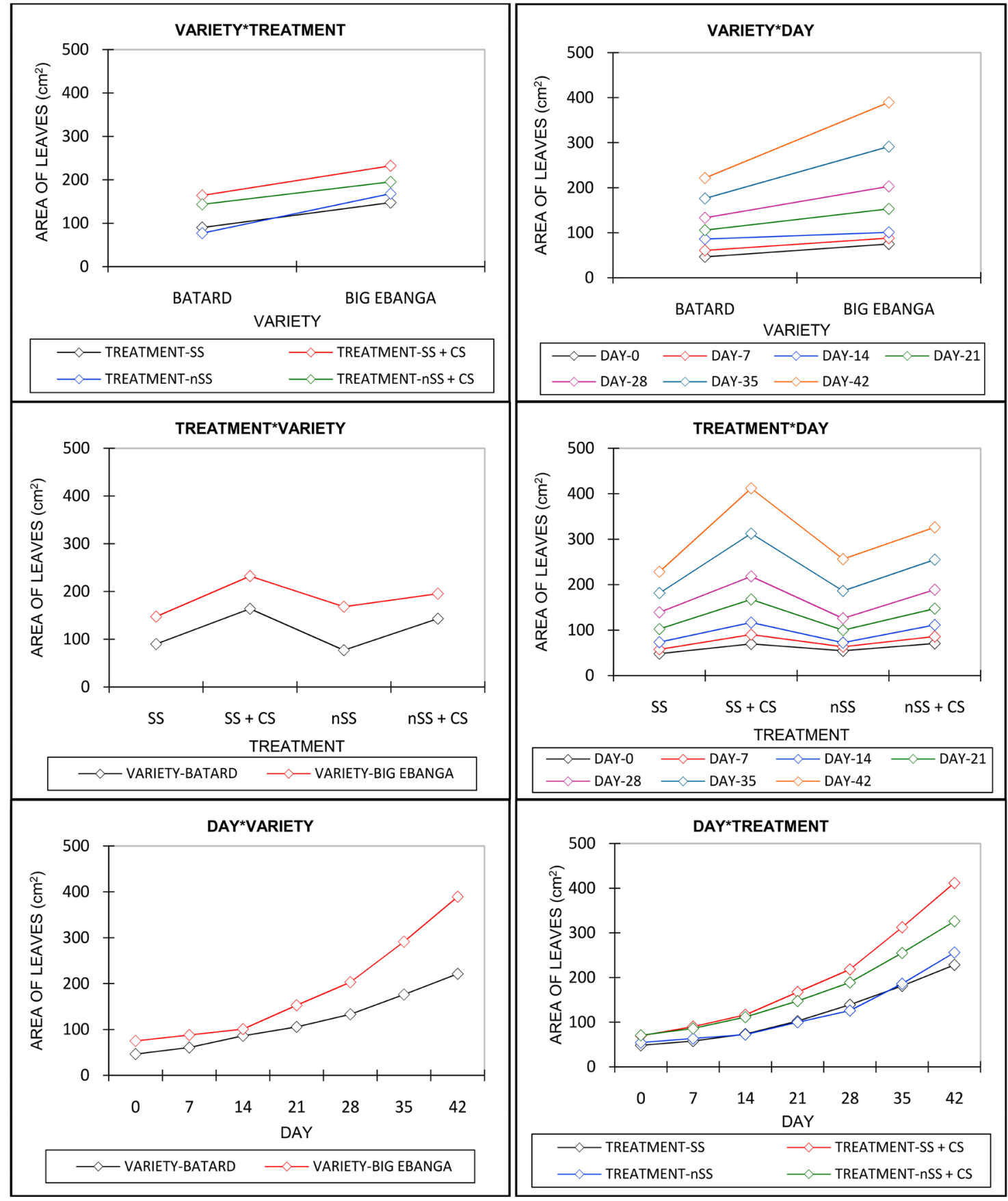

Figure 5. Interaction plots (variety, treatment and day) of the clam shells effects on the plantain PIF seedlings leaves surface area in both varieties (Batard and Big Ebanga) in course of time. Each point represents the average mean of three replicates for each treatment. 


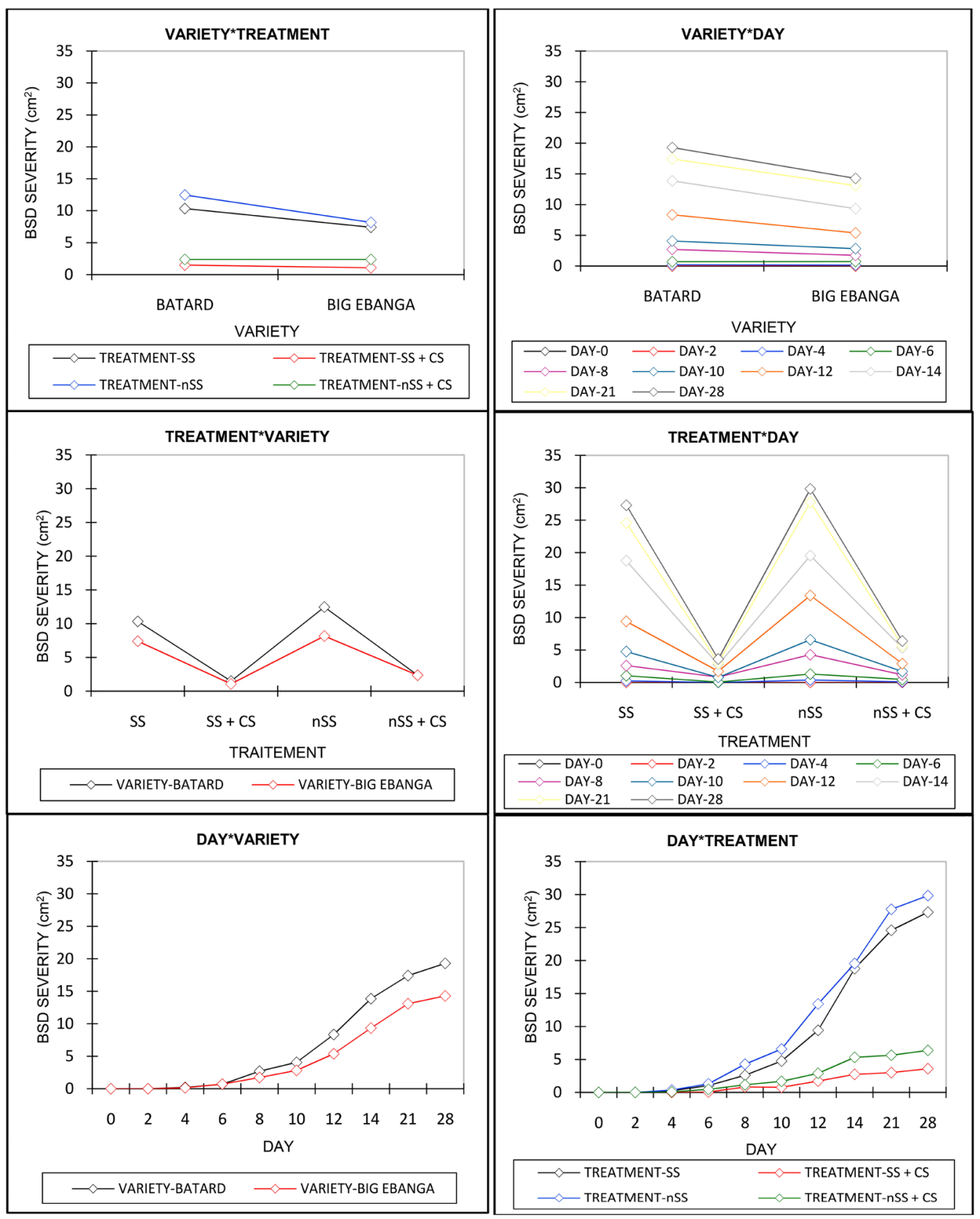

Figure 6. Interaction plots (variety, treatment and day) of the clam shells effects on the plantain PIF seedlings susceptibility to BSD in both varieties (Batard and Big Ebanga) in course of time. Each point represents the average mean of three replicates for each treatment.

\subsubsection{Effect of Clam Shells on Proteins and Polyphenols Accumulation in PIF Seedlings}

The treatment and the stage were found to very significantly influence $(P<$ $0.0001)$ proteins accumulation $\left(\mathrm{R}^{2}=0.94\right)$ in PIF seedlings while the ones influencing very significantly the polyphenols accumulation $\left(R^{2}=0.99\right)$ in PIF seedlings were the variety, the treatment and the stage (Table 5). The most influential variable in the accumulation of proteins and polyphenols was the stage for the Batard variety and the treatment for the Big Ebanga variety. The proteins 
Table 5. Variance analysis of clam shells treatments effects on the accumulation of proteins and polyphenols in plantain PIF seedlings for both stages (before inoculation and after inoculation).

\begin{tabular}{|c|c|c|c|c|c|c|}
\hline \multirow[b]{2}{*}{ Source } & \multicolumn{3}{|c|}{$\begin{array}{c}\text { Total proteins } \\
(\mathrm{mg} \mathrm{Eq} \mathrm{BSA} / \mathrm{g} \mathrm{FW}) / \mathrm{R}^{2}=94 \%\end{array}$} & \multicolumn{3}{|c|}{$\begin{array}{c}\text { Total polyphenols } \\
(\mathrm{mg} \mathrm{Eq} \mathrm{Cat} / \mathrm{g} \mathrm{FW}) / \mathrm{R}^{2}=99 \%\end{array}$} \\
\hline & $\mathrm{DF}$ & $F$ & $P$ & $\mathrm{DF}$ & $F$ & $P$ \\
\hline Variety & 1 & 0 & 1 & 1 & 1459 & $<0.0001$ \\
\hline Treatment & 3 & 26 & $<0.0001$ & 3 & 263 & $<0.0001$ \\
\hline Stage & 1 & 248 & $<0.0001$ & 1 & 196 & $<0.0001$ \\
\hline Variety*treatment & 3 & 7 & 0 & 3 & 163 & $<0.0001$ \\
\hline Variety*stage & 1 & 162 & $<0.0001$ & 1 & 19 & 0 \\
\hline Treatment ${ }^{\star}$ stage & 3 & 1 & 0 & 3 & 3 & 0 \\
\hline Variety ${ }^{*}$ treatment ${ }^{*}$ stage & 3 & 1 & 1 & 3 & 6 & 0 \\
\hline
\end{tabular}

$\mathrm{DF}$ is the degree of freedom; $F$ is the value of $\mathrm{F}$ test and $P$ is the probability.

and polyphenols amounts were high in the treated PIF substrates compared with the untreated ones regardless of the stage. Hence, two statistically very different groups were distinguished between the treated and the untreated PIF seedlings. The difference between the amount of proteins and polyphenols accumulated in the controlled condition (SS and SS + CS) and non-controlled condition (nSS and $\mathrm{nSS}+\mathrm{CS}$ ) was very low (Table 1 ).

The stage effect was especially marked for the Batard variety that had seedlings with consistent amount of proteins and polyphenols after inoculation compared to the amount before inoculation as confirmed by the significant interaction $(P<0.0001)$ between variety and stage.

For proteins accumulation, no significant interaction was observed between variety, treatment and stage (Table 5, Figure 7 and Figure 8).

The treatment effect was especially marked for the Big Ebanga variety that had seedlings with consistent amount of proteins and polyphenols before and after inoculation in the treated seedlings compared to the untreated ones as confirmed by the significant interaction $(P<0.0001)$ between variety and treatment (Table 5, Figure 7 and Figure 8).

The amount of proteins before inoculation in the Batard variety PIF seedling was inversely proportional to the one after inoculation regardless of the treatment, while the polyphenols amount was more important in the Big Ebanga variety PIF treated seedling after inoculation (Figure 7 and Figure 8).

\subsection{Pearson Correlation Analysis between the Different Variables}

The patterns found in the scatter plots indicate that the total proteins and total polyphenols in the Big Ebanga variety were negatively correlated with the agromorphological characteristics (height of shoots, diameter of pseudo-stems and 
area of leaves) and BSD severity, while in the Batard variety only the total polyphenols was negatively correlated with all these variables (Figure 9). Furthermore, a strong positive correlation was found between the agromorphological characteristics (height of shoots, diameter of pseudo-stems and area of leaves). It was evidenced that height of shoots, diameter of pseudo-stems and area of leaves where positively correlated to BSD severity in both varieties; as well as proteins content for the Batard variety, poorly linked to these variables.

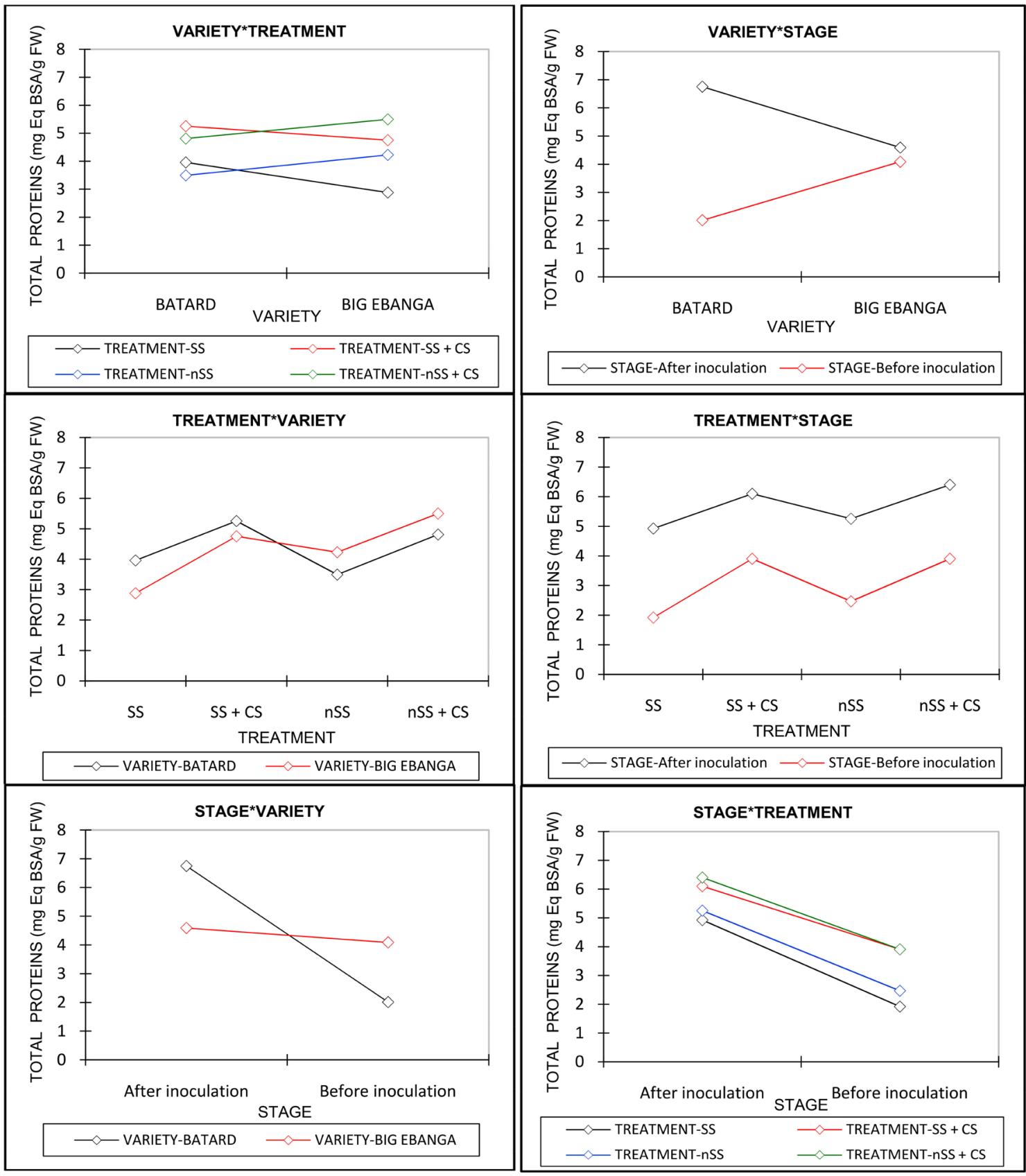

Figure 7. Interaction plots (variety, treatment and day) of the clam shells effects on the plantain PIF seedlings accumulation of total proteins in both varieties (Batard and Big Ebanga) and at both stages (before inoculation and after inoculation). Each point represents the average mean of three replicates for each treatment. 


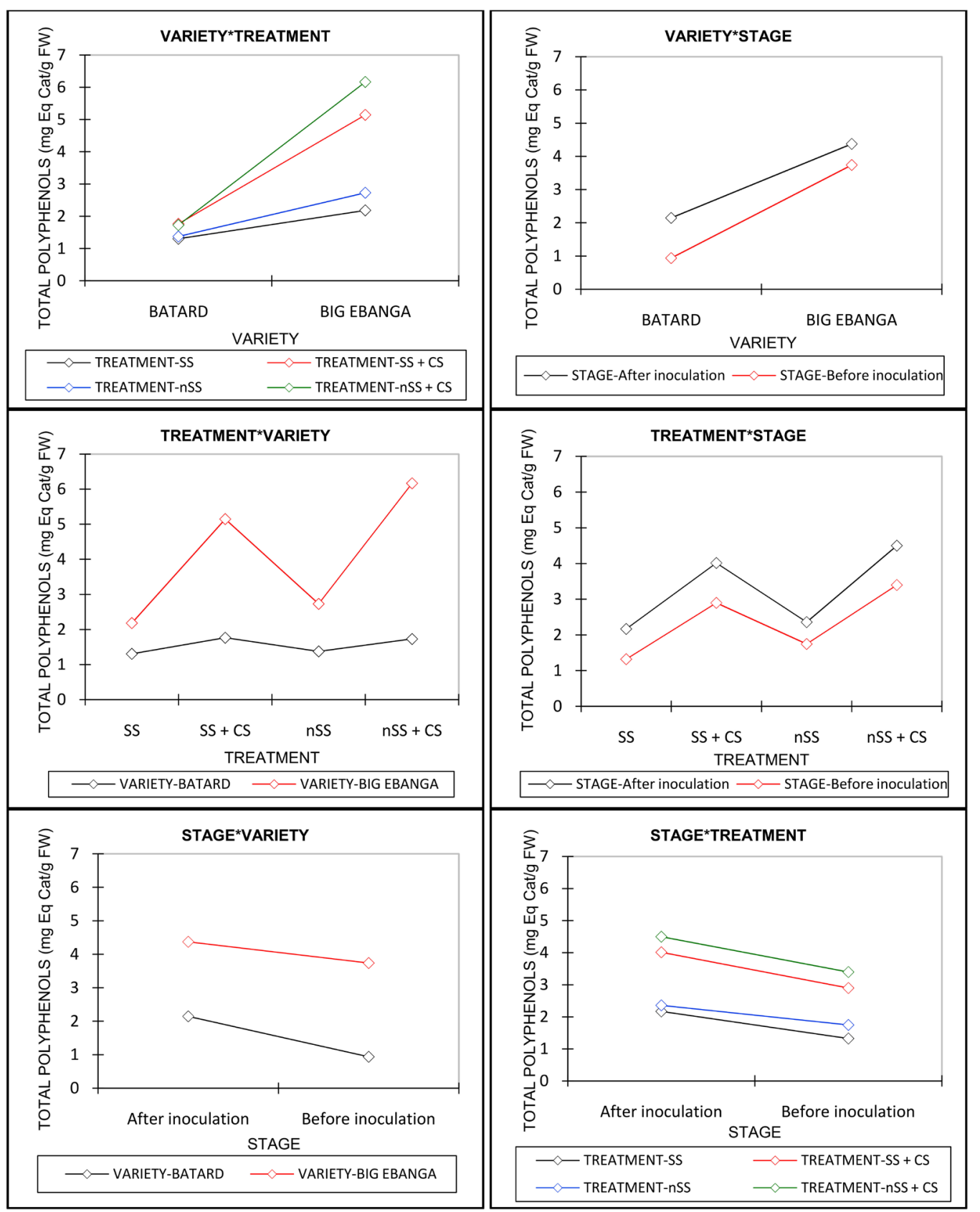

Figure 8. Interaction plots (variety, treatment and day) of the clam shells effects on the plantain PIF seedlings accumulation of total polyphenols in both varieties (Batard and Big Ebanga) and at both stages (before inoculation and after inoculation). Each point represents the average mean of three replicates for each treatment.

\section{Discussion}

It was hypothesized that clam shells treatment could biostimulate the growth of plantain PIF seedlings and their susceptibility to black Sigatoka disease. Our data confirmed this hypothesis and provided evidence for wide variations in the germination rate, in the growth characteristics (number of shoots, height of shoots, diameter of pseudo-stems, area of leaves, length of roots), in the susceptibility to 

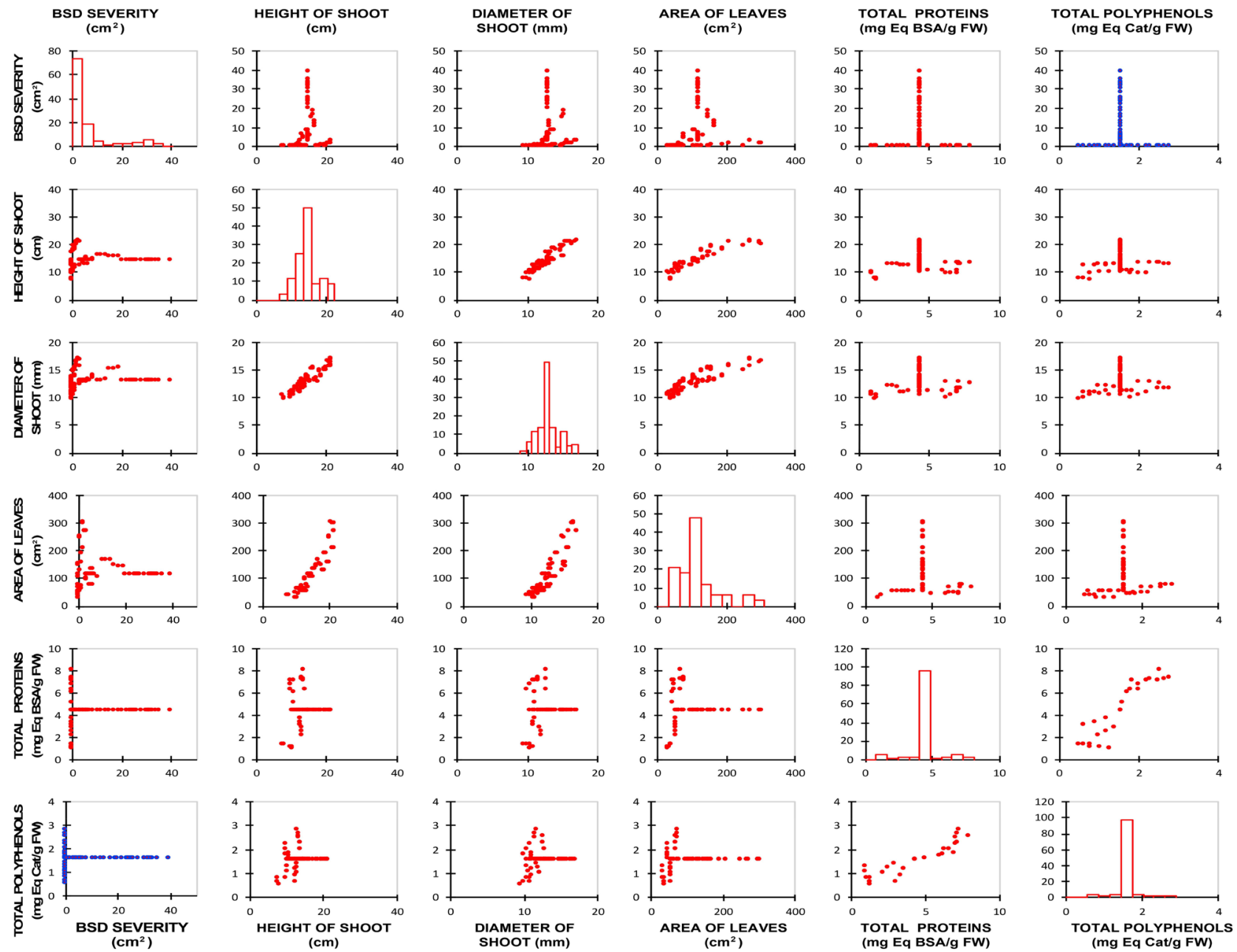

(a) 

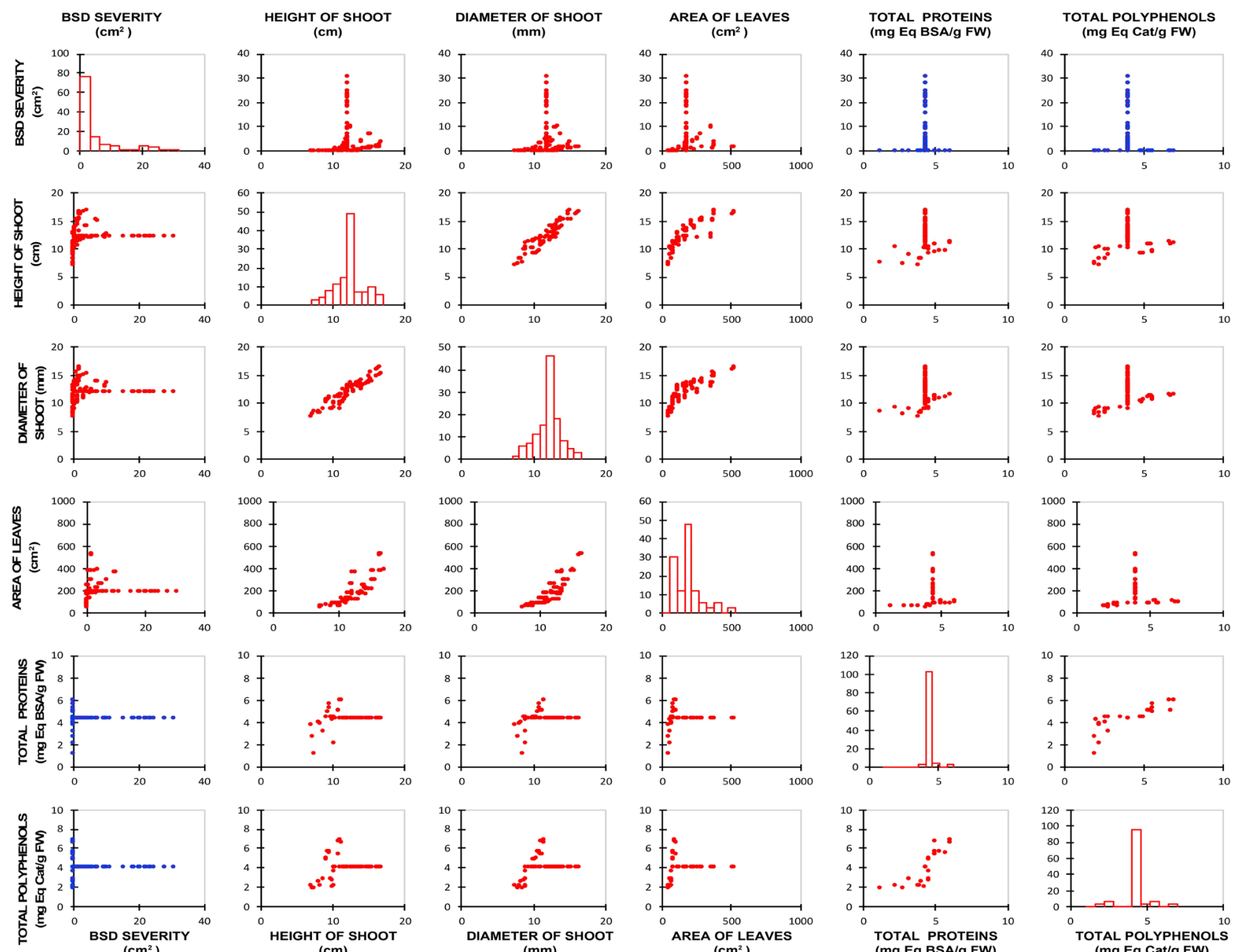

(b)
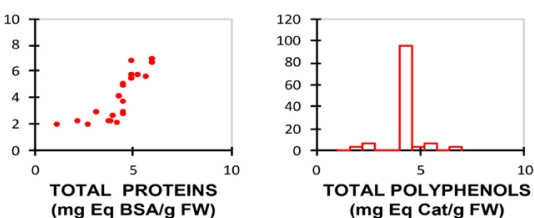

Figure 9. Scatter plots showing positive (red) or negative correlation (blue) but also the strength of the relationship between the variables (height of shoots, diameter of pseudo stems, area of leaves, BSD severity, total proteins and total polyphenols) in plantain PIF seedlings of the Batard (a) and the Big Ebanga (b) varieties.

Shells, chitin sources and derivatives (chitin and chitosan-based polymers) contents chitin, calcium and magnesium carbonate, protein ... [10]. It has been shown that this content provides excellent protection against diseases and has influence on growth promoting components, yield, thousand seeds weight and reduced post-harvest disease incidence and percent disease index [8] [22]. Due to its high nitrogen content and low carbon-nitrogen ratio $(\mathrm{C} / \mathrm{N})$, chitin can be directly used as a fertilizer to enhance crop growth [8]. The sufficient nitrogen availability in chitin seems to stimulate the seed germination especially in the Batard variety, the number of shoots generated notably for the Big Ebanga variety and the seedlings growth of both varieties through its direct role in plant nutrition. Clam shells seem to act in the plantain PIF substrate as a biostimulator that induces different reactions leading to the accumulation of nutrients important for the stimulation of plant growth. 
Beneficial effects of clam shells treatment start from the positive modification of the soil physicochemical and biological characteristic to the interaction between the substrate, the plant and the plant microbiome. Indeed, plant roots are surrounded by a thin film of soil called the rhizosphere which represents the primary location of nutrient uptake, and is also where important physiological, chemical, and biological activities are occurring [27]. Moreover, the addition of chitin to the soil also improves microbial communities in both the abundances and structures [8]. It would be interesting to identify the microbiome of plantain PIF substrate amended with clam shells and the potential antagonistic and synergistic interactions.

The significant less susceptibility to BSD of the treated plantain PIF seedlings compared to the control ones in both varieties 28 days after inoculation (dai) have been shown in this study. Bananas are commonly known as being susceptible to BSD [14] but these two plantain varieties respond to the treatment through a less susceptibility to $M$. fijiensis. The treatment seems to generate a tolerance against BSD pathogen, suggesting thus a protective role of clam shells. Indeed, the clam shells treatment in the PIF seedlings reaches up to $86.3 \%$ and $87.5 \%$ of protection 28 dai respectively in the Batard and the Big Ebanga varieties compared to the control ones in the sterile condition (SS). The less susceptibility observed for the treated plantain PIF seedlings could be due to the fact that chitin present in the PIF treated substrate is recognized by specific receptors present on the plant cell plasma membrane, such as the pathogen-associated molecular pattern (PAMP) receptor and this recognition can activate PAMPtriggered immunity that is able to induce defense responses [28], notably systemic acquired defense. This protective effect could probably be effective for other potential phytopathogens and need to be accessed. Our results also show that the Big Ebanga variety is less susceptible to BSD in the nursery compare to the Batard variety. Since the BSD severity increase with the plant ages [29], it would be interesting to access this clam shells protective effect on plantain seedlings at different ages.

Some proteins and polyphenols were present in plantain PIF seedling before inoculation and were considered constitutive compounds in contrast to de novo ones produced after inoculation. The amount of constitutive proteins and polyphenols compounds in the Big Ebanga variety is more important than in the Batard variety and it rises significantly after inoculation especially for the total proteins of the Batard variety. It is known that phenolics compounds have different rates of accumulation depending on whether plant pathogen interaction is compatible or incompatible [30], and low level of phenolics is link to diseases susceptibility. Therefore, the Big Ebanga has constitutive important pool of proteins and polyphenols that seems to be enough to participate in defense reactions and to overcome infection without large amount of de novo synthesis as compared to the proteins in the Batard variety. Our results are in accordance with a previous study where a significant improvement in total proteins and phenolics, and other compounds was observed when banana plants where fertilized with 
feather degradation products [31].

In the case of Batard variety, a positive correlation was found between the total amount of proteins before and after inoculation, and all the agromorphological variables which are involved in their growth promotion and BSD severity, while it was negative for the total polyphenol's ones. In the Big Ebanga variety, a negative correlation was found between the total proteins and polyphenols, and all the variables; it is unfortunately not link to the enhance growth characteristic and the BSD severity observed. A lack in this study lies in the fact that 28 dai seem to be almost too late for the assessment of the biochemical events occurring in plantain PIF seedlings in the first hours and days after inoculation and the establishment of infections. Moreover, it cannot be determined if there was fluctuation in the quantity of proteins and polyphenols between the stage before inoculation and 28 dai and/or potential positive correlation between the agromorphological characters, BSD severity and the biochemical compounds accumulated, putting to question, the early biochemical reactions that occurs in plantain PIF seedlings after inoculation with $M$. fijiensis.

The treatment of PIF substrate with $1 \%$ clam shells for both varieties seems to have induced the synthesis of polyphenols which act either as chemical or physical barriers to $M$. fijiensis. Indeed, plant antifungal metabolites are preformed inhibitors that are constitutively produced in healthy plants (phytoanticipins), or they may be synthesized de novo in response to pathogen attack or various non-biological stress factors [28] [32]. Our data confirmed results of earlier studies, which found an increase in phenolics identified in banana tissues, considered as chemical or physical barriers and they play key roles in the defense against pathogens infection [33] [34] [35] [36]. The important phenolic content of plantain PIF seedlings treated with $1 \%$ clam shells especially for the Big Ebanga variety could thus be explained by the fact that they behave as markers of resistance to diseases. Therefore, they could be part of the biochemical response of the mechanism involved in the less susceptibility of treated plantain PIF seedlings to BSD.

Clam shells treatment has promoted growth and induced PIF seedlings resistance against $M$. fijiensis and this could be effective through his indirect role in plant as for plant-growth promoting rhizobacteria (PGPR). The direct mechanism of PGPR include the synthesis of many secondary metabolites, hormones, cell-wall-degrading enzymes, and antioxidants that assist the plant in its defense against pathogen attack, while indirectly it includes the stimulation of plant growth and the induction of acquired systemic resistance [27]. Therefore, there is a need to access the physiological mechanism involves in clam shells effect on growth promotion and protection against diseases in plantain PIF seedlings.

\section{Conclusion}

In the level of the greenhouse and shade (nursery), our $1 \%$ clam shells treatment enhances efficiently plantain PIF seedlings vigor and can thus reduce signifi- 
cantly mortality in the fields level. Our results have shown that clam shells treatment is able to play a dual role (biofertilizer and biopesticide) in plant growth positive regulation and improved defense responses on plantain PIF seedlings against phytopathogens in terms of germination rate, number of shoots, length of shoots, diameter of pseudo-stems, area of leaves, BSD severity, proteins and polyphenols accumulation. It would be interesting to investigate the biochemical and molecular mechanisms involved in clam shells growth promotion and induced resistance against pathogens, as well as set up fields trials to understand the bioactivity of clam shells notably possible synergistic and antagonistic interactions. Hence, this study should be the starting point of the improvement of plantain PIF seedlings quality in terms of growth and less susceptibility to diseases.

\section{Conflicts of Interest}

The authors declare no conflicts of interest regarding the publication of this paper.

\section{References}

[1] Lassoudière, A. (2007) Le bananier et sa culture. Editions Quae.

[2] FAO (2017) Food and Agriculture Organization of the United Nations. FAO Statistics: Bananas. http://www.fao.org/faostat/en/\#data/QC

[3] The World Bank (2018) Breaking Down the Barriers to Regional Agricultural Trade in Central Africa. World Bank Publications, Washington DC.

[4] CARBAP (2002) Création et conduite d'une Bananeraie au Cameroun; le Cas du Bananier Plantain. Fiche Technique, Njombé.

[5] Kwa, M. (2002) Techniques horticoles de production de masse de plants de banane: La technique des plants issus de fragments de tige (PIF). Fiche technique CARBAP.

[6] Ewané, C.A., Chillet, M., Castelan, F., Brostaux, Y., Lassois, L., Ngando, E.J., Hubert, O., Chilin-Charles, Y., Lepoivre, P. and de Lapeyre de Bellaire, L. (2013) Impact of the Extension of Black Leaf Streak Disease on Banana Susceptibility to Post-Harvest Diseases. EDP Sciences. Fruits, 68, 351-365.

https://doi.org/10.1051/fruits/2013081

[7] Onautshu, O.D. (2013) Caractérisation des populations de Mycosphaerella fijiensis et épidémiologie de la cercosporiose noire du bananier (Musa spp.) dans la région de Kisangani-République Démocratique du Congo. Thèse de doctorat ès science, Université Catholique de Louvain, Belgium.

[8] Malerba, M. and Cerana, R. (2019) Recent Applications of Chitin- and Chitosan-Based Polymers in Plants. Polymers, 11, 839.

https://doi.org/10.3390/polym11050839

[9] Téné Tayo, P.M., Ewané, C.A., Effa, O.P. and Boudjeko, T. (2017) Effects of Chitosan and Snail Shell Powder on Cocoa (Theobroma cacao L.) Growth and Resistance against Black Pod Disease Caused by Phytophthora Megakarya. African Journal of Plant Science, 11, 331-340. https://doi.org/10.5897/AJPS2016.1487

[10] Khoushab, F. and Yamabhai, M. (2010) Chitin Research Revisited. Marine Drugs, 8, 1988-2012. https://doi.org/10.3390/md8071988

[11] Melegari, S.P. and Matias, W.G. (2012) Preliminary Assessment of the Performance 
of Oyster Shells and Chitin Materials as Adsorbents in the Removal of Saxitoxin in Aqueous Solutions. Chemistry Central Journal, 6, 86. https://doi.org/10.1186/1752-153X-6-86

[12] du Jardin, P. (2015) Plants Biostimulants: Definition, Concept, Main Categories and Regulations. Scientia Horticultura, 196, 3-14. https://doi.org/10.1016/j.scienta.2015.09.021

[13] Abessolo, A.P. (2012) Guide pratique de production de rejets de bananier plantain par la methode P.I.F. Manuel de formation pour les groupes de producteurs agricoles.

[14] Ewané, C.A., Lassois, L., Brostaux, Y., Lepoivre, P. and de Lapeyre de Bellaire L. (2012b) The Susceptibility of Bananas to Crown Rot Disease Is Influenced by Geographic and Temporal Effects. Canadian Journal of Plant Pathology, 35, 27-36. https://doi.org/10.1080/07060661.2012.733731

[15] Pirovani, P.C., Heliana, A.S.C., Regina, C.R., Dayane, S.G., Fatima, C.A. and Fabienne, M. (2008) Protein Extraction for Proteome Analysis from Cacao Leaves and Meristems, Organs Infected by Moniliophthora perniciosa, the Causal Agent for the Witches' Broom Diseases. Electrophoresis Journal, 29, 2391-2401. https://doi.org/10.1002/elps.200700743

[16] Bradford, M.M. (1976) A Rapid and Sensitive Method for the Quantification of Microgram Quantities of Protein Utilizing the Principle of Protein-Dye Binding. Annals of Biochemistry, 72, 248-254. https://doi.org/10.1006/abio.1976.9999

[17] El Hadrami, I. and Baaziz, M. (1997) Somatic Embryogenesis and Analysis of Peroxydase in Phoenix dactylifera L. Biologia Plantarum, 37, 197-203. https://doi.org/10.1007/BF02913210

[18] Marigo, G. (1973) Méthode de fractionnement et d'estimation des composés phénoliques chez les végétaux. Analysis, 12, 106-110.

[19] Martínez, M.M., Ortega, R., Janssens, M. and Fincheira, P. (2018) Use of Organic Amendments in Table Grape: Effect on Plant Root System and Soil Quality Indicators. Journal of Soil Science and Plant Nutrition, 18, 100-112. https://doi.org/10.4067/S0718-95162018005000501

[20] Téné Tayo, P.M., Dzelamonyuy, A., Omokolo, N.D. and Boudjeko, T. (2019) Enhancement of Theobroma cacao Seedling Growth and Tolerance to Phytophthora megakarya by Heat-Treated Oyster Shell Powder. American Journal of Plant Sciences, 10, 578-594. https://doi.org/10.4236/ajps.2019.104042

[21] Zhou, Y., Jiang, S., Jiao, Y. and Wang, H. (2017) Synergistic Effects of Nanochitin on Inhibition of Tobacco Root Rot Disease. International Journal of Biological Macromolecules, 99, 205-212. https://doi.org/10.1016/j.ijbiomac.2017.02.069

[22] Akter, J., Jannat, R., Hossain, M.M., Ahmed. J.U. and Rubayet, T.M. (2018) Chitosan for Plant Growth Promotion and Disease Suppression against Anthracnose in Chilli. International Journal of Environment, Agriculture and Biotechnology, 3, 806-817. https://doi.org/10.22161/ijeab/3.3.13

[23] Sathiyabama, M. and Manikandan, A. (2018) Application of Copper-Chitosan Nanoparticles Stimulate Growth and Induce Resistance in Finger Millet (Eleusine coracana Gaertn.) Plants against Blast Disease. Journal of Agricultural and Food Chemistry, 66, 1784-1790. https://doi.org/10.1021/acs.jafc.7b05921

[24] Egusa, M., Matsui, H., Urakami, T., Okuda, S., Ifuku, S., Nakagami, H. and Kaminaka, H. (2015) Chitin Nanofibers Elucidates the Elicitor Activity of Polymeric Chitin in Plants. Frontiers in Plant Science, 6, 1098-1105.

https://doi.org/10.3389/fpls.2015.01098 
[25] Moyer, M.M., Gadoury, D.M., Cadle-Davidson, L., Dry, I.B., Magarey, P.A., Wilcox, W.F. and Seem, R.C. (2010) Effects of Acute Low Temperature Events on Development of Erysiphe necator and Susceptibility of Vitis vinifera. Phytopathology, 100, 1240-1249. https://doi.org/10.1094/PHYTO-01-10-0012

[26] Andersen, E.J., Ali, S., Byamukama, E., Yen, Y. and Nepal, M.P. (2018) Disease Resistance Mechanisms in Plants. Genes, 9, 339. https://doi.org/10.3390/genes9070339

[27] Hashem, A., Tabassum, B. and Fathi Abd_Allah, E. (2019) Bacillus subtilis. A Plant-Growth Promoting Rhizobacterium that also Impacts Biotic. Saudi Journal of Biological Sciences, 6 1291-1297. https://doi.org/10.1016/j.sjbs.2019.05.004

[28] Pusztahelyi, T. (2018) Chitin and Chitin-Related Compounds in Plant-Fungal Interactions. Mycology, 9, 189-201. https://doi.org/10.1080/21501203.2018.1473299

[29] Pérez-Vicente, L. (2012) A Holistic Integrated Management Approach to Control Black Sigatoka Disease of Banana Caused by Mycosphaerella fijiensis. Food and Agriculture Organization of the United Nations.

[30] Ewané, C.A., Lepoivre, P., De Lapeyre de Bellaire, L. and Lassois, L. (2012) Involvement of Phenolic Compounds in the Susceptibility of Bananas to Crown Rot. A Review. Biotechnologie, Agronomie, Société et Environnement, 16, 393-404.

[31] Gurav, R.G. and Jadhav, J.P. (2013) A Novel Source of Biofertilizer from Feather Biomass for Banana Cultivation. Environmental Science and Pollution Research, 20, 4532-4539. https://doi.org/10.1007/s11356-012-1405-Z

[32] Pusztahelyi, T., Holb, I.J. and Pócsi, I. (2015) Secondary Metabolites in Fungus-Plant Interactions. Frontiers in Plant Science, 6, 1-23.

https://doi.org/10.3389/fpls.2015.00573

[33] Collingborn, F.M.B., Gowen, S.R. and Mueller-Harvey, I. (2000) Investigations into the Biochemical Basis for Nematode Resistance in Roots of Three Musa Cultivars in Response to Radopholus similis Infection. Journal of Agricultural and Food Chemistry, 48, 5297-301. https://doi.org/10.1021/jf000492z

[34] de Ascensao, A.R.F.D.C. and Dubery, I.A. (2003) Soluble and Wall-Bound Phenolics and Phenolic Polymers in Musa acuminata Roots Exposed to Elicitors from Fusarium oxysporum f.sp. Cubense. Phytochemistry, 63, 679-686. https://doi.org/10.1016/S0031-9422(03)00286-3

[35] Wuyts, N., Lognay, G., Verscheure, M., Marlier, M., De Waele, D. and Swennen, R. (2007) Potential Physical and Chemical Barriers to Infection by the Burrowing Nematode Radopholus similis in Roots of Susceptible and Resistant Banana (Musa spp.). Plant Pathology, 56, 878-890. https://doi.org/10.1111/j.1365-3059.2007.01607.x

[36] Ewané, C.A. (2012) Étude de la composante physiologique impliquée dans le développement des pourritures de couronne de bananes et rôle des composés phénoliques dans les mécanismes de variation de sensibilité. Thèse de Doctorat ès science soutenue en décembre 2012 à GxABT-ULg (Gembloux Agro-Bio Tech-Université de Liège)-Belgique. 